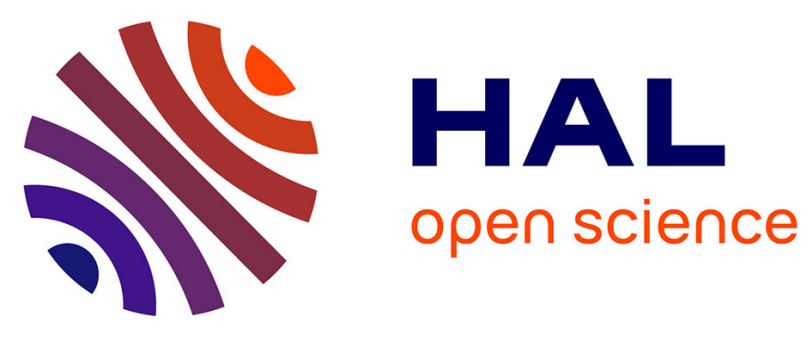

\title{
CT-Guided Percutaneous Gastrostomy without Preliminary Placement of a Nasogastric Tube
} Xiong-Ying Jiang, Anne-Sophie Bertrand, Guo Li, Christophe Hebert, Pierre-Yves Marcy, Marie-Noëlle Falewee, Antoine Iannessi

\section{- To cite this version:}

Xiong-Ying Jiang, Anne-Sophie Bertrand, Guo Li, Christophe Hebert, Pierre-Yves Marcy, et al.. CTGuided Percutaneous Gastrostomy without Preliminary Placement of a Nasogastric Tube. JVIR: Journal of Vascular and Interventional Radiology, 2019, 30, pp.915 - 917. 10.1016/j.jvir.2018.08.014 . hal-03484968

\section{HAL Id: hal-03484968 \\ https://hal.science/hal-03484968}

Submitted on 20 Dec 2021

HAL is a multi-disciplinary open access archive for the deposit and dissemination of scientific research documents, whether they are published or not. The documents may come from teaching and research institutions in France or abroad, or from public or private research centers.
L'archive ouverte pluridisciplinaire HAL, est destinée au dépôt et à la diffusion de documents scientifiques de niveau recherche, publiés ou non, émanant des établissements d'enseignement et de recherche français ou étrangers, des laboratoires publics ou privés.

\section{(ㄷ)(1) $\$$}

Distributed under a Creative Commons Attribution - NonCommerciall 4.0 International 


\section{Title Page}

Title: CT guided percutaneous gastrostomy without preliminary placement of a nasogastric tube.

Authors: Xiong-ying Jiang ${ }^{1,2}$, Anne-Sophie Bertrand ${ }^{1}$, Guo Li ${ }^{1,3}$, Christophe Hebert ${ }^{4}$, Pierre-Yyves Marcy ${ }^{1}$, Marie-Noëlle Falewee ${ }^{5}$, Antoine Iannessi ${ }^{1}$,

Authors' Affiliations: ${ }^{1}$ Department of Interventional and Diagnostic Imaging,

Cancer Center Antoine Lacassagne, Nice, 06189, France; ${ }^{2}$ Department of

Interventional Radiology, Sun Yat-sen Memorial Hospital, Sun Yat-sen University,

Guangzhou, 510120, P. R. China; ${ }^{3}$ Department of Radiotherapy, Cancer Center of

Guangzhou Medical University, Guangzhou, Guangdong 510095, P. R. China;

${ }^{4}$ Department of Oncology, Cancer Center Antoine Lacassagne, Nice, 06189, France;

${ }^{5}$ Department of Nutrition, Cancer Center Antoine Lacassagne, Nice, 06189, France

Corresponding Author: Antoine Iannessi, Department of Interventional and Diagnostic Imaging, Cancer Center Antoine Lacassagne, Nice, 06189, France. Tel: +33-629434650 2. Email: antoineiannessi@gmail.com.

Acknowledgments: The authors received no specific funding for this work.

Conflict of Interest Notification: There are no any actual or potential conflicts of interest exist.

\section{Author Contribution:}

Study design: Antoine Iannessi

Operative participant: Antoine Iannessi, Xiong-ying Jiang, Anne-Sophie Bertrand

Data collection: Xiong-ying Jiang, Christophe Hebert, Marie-Noëlle Falewee 
Manuscript writing: Xiong-ying Jiang, Guo Li, Pierre-Yyves Marcy, Anne-Sophie

Bertrand

Constructive suggestions: Guo Li, Anne-Sophie Bertrand, Pierre-Yyves Marcy

Final approval of the manuscript: Antoine Iannessi 
Title: CT guided percutaneous gastrostomy without preliminary placement of a nasogastric tube

Abstract: Formal percutaneous radiologic gastrostomy (PRG) procedures require preliminary gastric room air inflation through a nasogastric tube (NGT) to safely perform gastric puncture. However, in case of upper aerodigestive obstruction, NGT placement can be impossible even using hydrophilic angiography catheter and wire to cross over the stenosis. This brief report describes percutaneous CT-guided gastrostomy with a 2-stick approach in 13 patients without nasogastric insufflation. Technical success was $100 \%$ with a number of $1.8( \pm 1.0)$ punctures access the gastric lumen. Traversal of the colon and liver with a $22 \mathrm{G}$ needle was necessary in 4 and 1 patients, respectively. There were no major complications. Minor complications were in 6 patients (46\%). CT guided percutaneous gastrostomy is technically feasible with minimal morbidity.

\section{Introduction}

Percutaneous radiologic gastrostomy (PRG) is a widely used technique for enteral nutrition and bowel decompression which usually requires inflation of the stomach via a naso-gastric tube (NGT). Patients with head and neck and esophageal cancers present a challenge as passage of a standard NGT or even a 5 French angiographic catheter may not be possible. The aim of this study was to describe the safety and efficacy of CT guided percutaneous gastrostomy in patients with decompressed stomachs in whom a nasogastric tube could not be placed. A 2-stick 
approach, initial cannulation of the stomach with a $22 \mathrm{G}$ needle and carbon dioxide insufflation and second $18 \mathrm{G}$ needle was used with gastropexy.

\section{Materials and Methods}

This single institution retrospective study was approved by the IRB. Between November 2014 to March 2018 passage of a standard 8 French nasogastric tube and subsequently a 5 French angiographic catheter with a hydrophilic guidewire by an interventional radiologist under fluoroscopic guidance was not possible in 13 patients (Ages 54-92, male $n=8$ ) referred for percutaneous gastrostomy. First causes for gastrostomy were primary head and neck cancer $(n=9)$ and esophageal cancer $(n=4)$.

All patients were kept fasting for 12 hours and received $1 \mathrm{~g}$ of ceftriaxone IV 30 minutes before procedure. Glucagon $10 \mathrm{mg}$ was administered to reduce gastric motility immediately before the procedure.

A CT scan of the upper abdomen was to evaluate the percutaneous track to the stomach lumen (Fig 1). Following sterile preparation and injection of $1 \%$ lidocaine subcutaneously, a $12 \mathrm{~cm}$, long 22G needle (Cook, Bloomington, Indiana) was used to access and inflate the gastric lumen with carbon dioxide under CT fluoroscopy. In those patients without a visible gastric lumen, the needle was advanced through both anterior and posterior walls and then withdrawn slowly while injecting carbon dioxide by hand (Fig 2 and 3). When CT confirmed intra gastric location of the fine needle tip, a further $300 \mathrm{mls}$ of carbon dioxide were injected inflating the stomach, apposing the anterior gastric and abdominal walls (Fig 4). Four gastropexy sutures (Halyard Health, Alpharetta, Georgia) were then deployed. The gastric lumen was accessed with 
18-gauge needle under CT guidance and the tract dilated with placement of a 20 French peel away sheath, through which a 16 French button gastrostomy (MIC-KEY, Ballard, Draper, Utah) was inserted.

Enteral feeding was commenced within 24 hours of gastrostomy placement. All patients were reviewed prior to hospital discharge and again at 15 days, 1 month and 3 months. Procedure complications were classified as major and minor according to SIR guide lines (1).

\section{Results}

Technical success for gastrostomy placement using the 2-stick technique was $100 \%$. In $8 / 13$ patients traversal of both anterior and posterior gastric walls with a $22 \mathrm{G}$ needle was necessary because the gastric lumen was not visible on CT. The initial fine needle tracks were transcolonic $(\mathrm{N}=4)$, transhepatic $(\mathrm{N}=1)$ and through the intercostal space $(\mathrm{N}=1)$ and these were well tolerated. Successful initial access to the gastric lumen was achieved with a mean of $1.8( \pm 1.0)$ needle passes with an overall, mean procedure duration of 20.9 minutes (+/-13.3) minutes.

There were no major complications. Minor complications occurred in 6 patients (46\%) which included carbon dioxide infiltration of the gastric wall $(n=5)$ (Fig3 and local bleeding $(n=1)$.

\section{Discussion}

This report describes a successful 2-stick technique for performing percutaneous gastrostomy under CT guidance in 13 patients in whom neither NG tube or fluoroscopic guided angiographic catheter placement for gastric inflation was possible. 
There were no major complications despite initial traversal of the colon and liver with a fine needle in four patients and one patient respectively.

While previous publications describe CT-guided gastrostomy, satisfactory gastric inflation was achieved by a variety of methods including NG tube, (2, 3). In patients without NG access, Heberlein described fluoroscopic guided access by direct puncture of a physiologically present gastric air bubble in $24 / 85$ patients and puncture of an effervescent-induced large gastric air bubble in the remaining 61 patients. (4). In a recent abstract, Yi et al performed US guided gastric puncture with $21 \mathrm{G}$ needle, followed by infusion of normal saline into the stomach, in 11 patients without nasogastric access (5). The US-guided puncture was then used for gastropexy followed by adjacent percutaneous gastrostomy/gastrojejunostomy.

The 2-stick technique has previously been described for percutaneous nephrostomy of nondilated renal collecting systems (6). After intravenous administration of iodinated contrast material, a 22-gauge needle was inserted into the opacified renal pelvis, and double-contrast pyelography was performed by using air or carbon dioxide to allow visualization and distention of the nondependent calyces for definitive renal access with an 18-gauge 5-F sheath-needle set.

The use of $\mathrm{CO} 2$ is preferred over air for gastric inflation because of more rapid resorption from the peritoneal cavity and the lower risk of embolism to the portal vein. However, several reports of air embolization to the portal veins following blunt abdominal trauma and barium enemas, have described the condition as clinically benign (7). 
Because of tube passage through the oropharynx, the pull placement technique for percutaneous gastrostomy has been associated with a high incidence of peristomal infectious complications (4\%-30\%), resulting in recommendations for routine prophylactic antibiotics for this procedure (SITR rec). In our study ceftriaxone was given prophylactically for visceral perforation such as traversal of colon with a fine needle (8).

In summary, percutaneous CT-guided gastrostomy using a 2-stick technique is safe and effective in patients without nasogastric access.

Submission declaration and verification: All authors have read and approved this version of the manuscript, and due care has been taken to ensure the integrity of the work. Neither the entire paper nor any part of its content has been published or has been accepted elsewhere. It is not being submitted to any other journal.

\section{References}

1. Cardella JF, Kundu S, Miller DL, et al. Society of interventional radiology clinical practice guidelines. Journal of Vascular and Interventional Radiology 2009; 20: S189-S191.10.1016/j.jvir.2009.04.035

2. Teichgräber UK-M, Streitparth F, Cho CH, et al. Percutaneous push-through gastrostomy by applying a ct-guided gastropexy. Journal of Vascular and Interventional Radiology 2011; 22: 1149-1152.10.1016/j.jvir.2011.02.037 3. Tamura A, Kato K, Suzuki M, et al. Ct-guided percutaneous radiologic gastrostomy for patients with head and neck cancer: A retrospective evaluation in 177 patients. CardioVascular and Interventional Radiology 2016; 39:

$271-278.10 .1007 / \mathrm{s} 00270-015-1170-8$ 
4. Heberlein WE, Goodwin WJ, Wood CE, et al. Gastrostomy tube placement without nasogastric tube: A retrospective evaluation in 85 patients. CardioVascular and Interventional Radiology 2012; 35: 1433-1438.10.1007/s00270-011-0321-9

5. Yi J, Hong H, Kim M, et al. Abstract no. 701 percutaneous radiologic gastrostomy/gastrojejunostomy placement without nasogastric access: Us-guided gastric puncture technique and evaluation of feasibility and safety. Journal of Vascular and Interventional Radiology 2018; 29: S288.10.1016/j.jvir.2018.01.746

6. Patel U, Hussain FF. Percutaneous nephrostomy of nondilated renal collecting systems with fluoroscopic guidance: Technique and results. Radiology 2004; 233: 226-233.10.1148/radiol.2331031342

7. NESHER E, AIZNER A, KASHTAN H, et al. Portal vein air embolization after blunt abdominal trauma: A case report and review of the literature. European Journal of Emergency Medicine 2002; 9: 163-165.

8. Venkatesan AM, Kundu S, Sacks D, et al. Practice guideline for adult antibiotic prophylaxis during vascular and interventional radiology procedures. Journal of Vascular and Interventional Radiology 2010; 21:

1611-1630.10.1016/j.jvir.2010.07.018

Figure.1: CT image shown non-contact between the gastric anterior wall and abdominal wall.

Figure.2: 22-gauge fine needle punctured into the gastric lumen.

Figure.3: $20 \mathrm{~mL}$ of carbon dioxide was injected into the gastric lumen through the fine needle. A small amount of carbon dioxide gas leaked into the gastric wall. Figure.4: The stomach was insufflated. A direct contact region between gastric anterior wall and abdominal wall was created. 


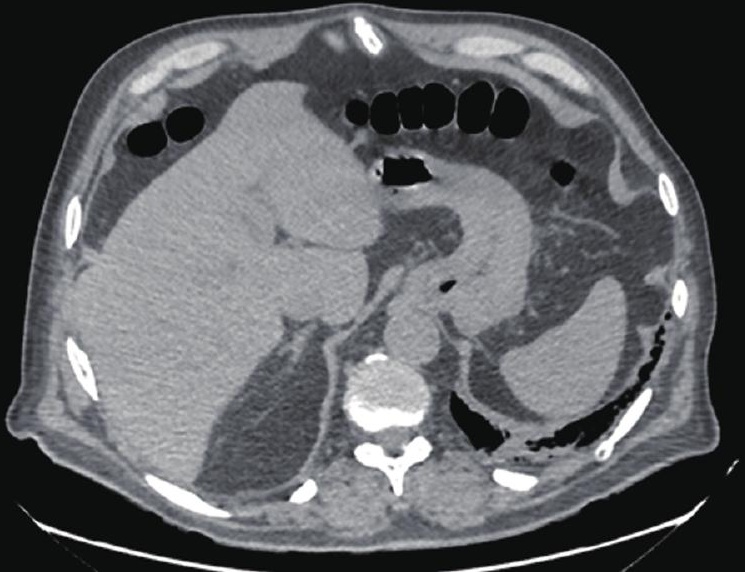




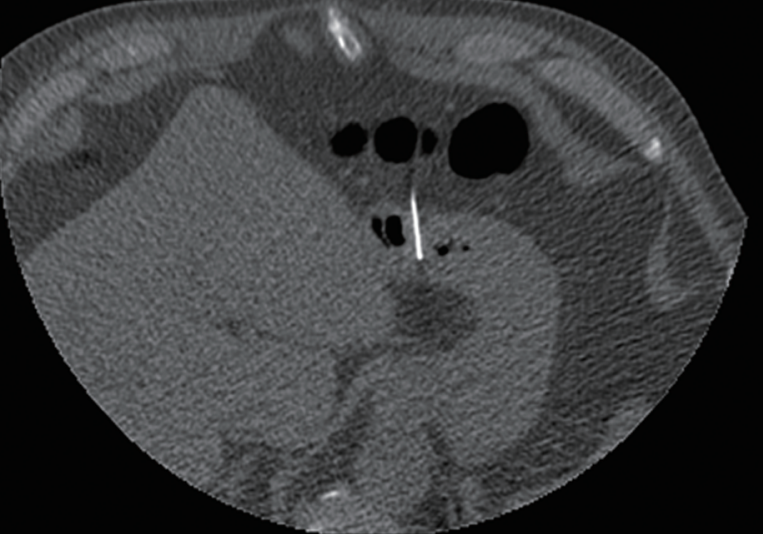




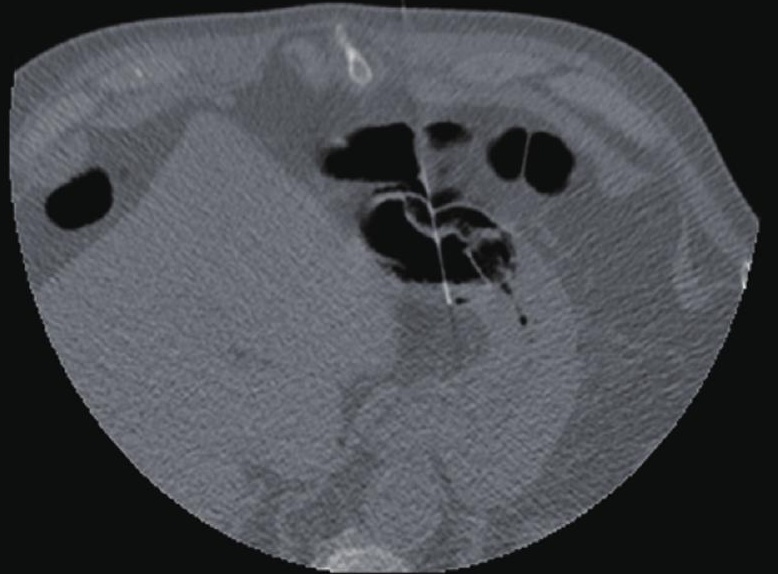




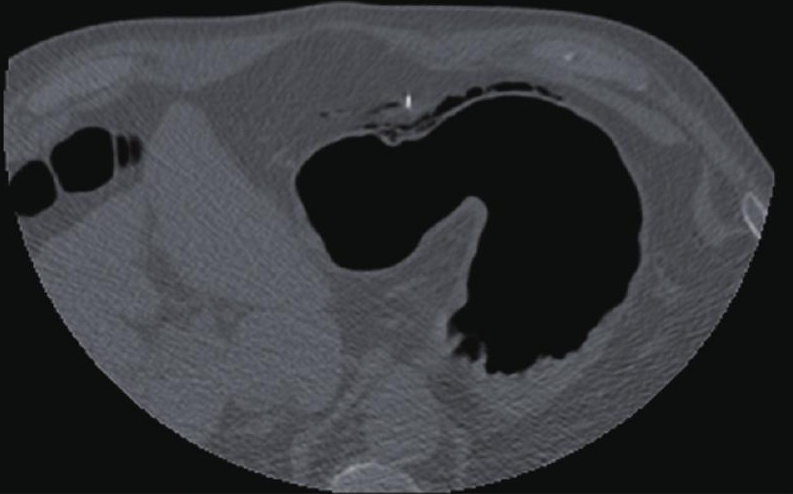

